\section{Biometric data assessment on Xenopus laevis tadpoles}

\author{
S. Slaby, ${ }^{1,2}$ J. Hanotel, ${ }^{1}$ J.-F. Bodart, ${ }^{1}$ \\ S. Lemiere, ${ }^{2}$ D. Trinel, ${ }^{1}$ A. Leprêtre, ${ }^{2}$ \\ C. Spriet, ${ }^{1}$ M. Marin \\ 'Univ. Lille, CNRS, INRA, UMR 8576 - \\ UGSF - Unité de Glycobiologie \\ Structurale et Fonctionnelle, Lille; \\ 2Univ. Lille Nord de France, EA 4515 - \\ LGCgE - Laboratoire Génie Civil et géo- \\ Environnement, Université de Lille 1, \\ Villeneuve-d'Ascq, France
}

\section{Introduction}

Recent studies stated that $41 \%$ of known species of amphibians are threatened. ${ }^{1}$ Indeed, their dramatic population decline is due to environmental conditions, including pollution. ${ }^{2,3}$ Their permeable skin and their close relationship with aquatic compartment, make them particularly sensitive to contamination and stand as strong models in biomonitoring studies. ${ }^{4}$ Consequently, the use of biomarkers in batrachians arose in the 80 ' $\mathrm{s}^{5}$ : from morphological and anatomical approaches (deformities, gonadic abnormalities) to biochemical measurements (vitellogenin, methallothionein, CYP450). ${ }^{4}$ For example, embryotoxic and teratogenic damages on larvae were detected with the FETAX (Frog Embryo Teratogenesis Assay - Xenopus) test developed in Xenopus laevis. ${ }^{6-8}$ In this regard, this specie appears as a very effective laboratory model for assays to dissect actions of chemical contamination. Indeed, profusion of data is available in cell cycle, embryology and development fields. ${ }^{9-}$ ${ }^{11}$ Moreover, our recent studies showed some different sub-individual modifications, especially a decrease of oocytes' capacity to perform the maturation and the fertilization in presence of cadmium. . $^{12,13}$

Here, we propose new methods to quantify the impacts of chemical contaminants on Xenopus laevis young tadpoles by recording biometric criteria.

\section{Materials and Methods}

All embryos were obtained by in vitro fertilization as described in our previous work. ${ }^{13}$ They were maintained in healthy or contaminated media, until 6 days (stage 42$)^{11}$ and fixated in ethanol $100^{\circ}$ at $-20^{\circ} \mathrm{C}$.

Then, tadpoles were stained in Alcian blue solution (0.1 mg. $\mathrm{L}^{-1}$ in acetic acid:ethanol 1:4) for 2 to 4 days according to the colour intensity wished. The background was removed by using a washing solution (chloridric acid:ethanol $70^{\circ}$ 1:99) for 1 to 2 days and tadpoles were progressively dehydrated in ethanol baths $\left(70^{\circ}, 95^{\circ}\right.$ and $100^{\circ}$ ) for $2 \mathrm{~h}$ each. Before the analysis process, biological materials were rehydrated in: water:ethanol 1:4, water:ethanol 1:1, MEM:ethanol 4:1 and MEM (MEM: $0.1 \mathrm{M}$ MOPS, 2 mM EGTA, $1 \mathrm{mM} \mathrm{MgSO}_{4}$, pH7.4). All steps were performed at room temperature. The tadpoles can be maintained in MEM for up to 3 days at $4^{\circ} \mathrm{C}$. All animal experiments were performed at the animal facility of Lille 1 University according to the rules of the European Community Council guidelines (86/609/EEC) for laboratory animal experimentation. The animal protocol was approved by the Local Institutional Review Board (Comité d'Ethique en Experimentation Animale NordPas- de-Calais, CEEA 07/2010).

Image enhancement, segmentation and morphological analysis were fulfilled using homemade plugin developed for Image $J,{ }^{14}$ as depicted in Figure 1. While image enhancement produces binary information such as spine integrity or brain appropriately developed regarding development stage, segmentation provides quantitative measurement of tadpole morphology. In this study, we focused on the tadpole's length (calculated based on the Feret's diameter, corresponding to the longest distance between two points of the selection boundary), perimeter, distance between eyes and position of the suction cup. Parameters can also be combined, normalizing measurements on animal and/or reference size to assess relative morphological differences.

\section{Results and Discussion}

Our new method provides numerous qualitative and quantitative data could be obtained. As depicted in Figure 2, a control tadpole (NT) was compared to treated ones (A, B and C). Morphological observations revealed abnormalities in terms of growth (tadpole A), dorsal curvature (tadpole B), or dorsal break and various edema (tadpole $\mathrm{C}$ ).

While traditional approaches focus only on growth, mortality and qualitative data, ${ }^{7}$ our method relies on extensive images enhancement automation and complete this qualitative approach with new biometric criteria, and thus for each suited tadpole. Figure 2D shows some of these measurements: length, perimeter, distance between the eyes (eyes) and the position of the suction cup.

To go even farther in the approach, in a second step of experiment, different tadpoles were compared. First normalization (grey bars, Figure 2D) was done in comparison with a
Correspondence: Matthieu Marin, SN3, 301, Université de Lille 1 F-59655 Villeneuve-d'Asca Cedex France.

E-mail: matthieu.marin@univ-lille1.fr

Key words: Xenopus laevis; tadpole; biosensor; biomarker; image analysis; biometry.

Funding: SS is a recipient for a doctoral fellowship from French ministry of higher education and research. $\mathrm{JH}$ is a recipient for a grant from the Nord-Pas-de-Calais Regional Council.

Acknowledgments: we are indebted to the Research Federation FRABio for providing the scientific and technical environment conductive to achieving this work. We also thank the personal of the TISBio Facility for access to the microscopy systems and technical advices.

Contributions: SS, JH, CS, MM, contributed equally to this work (co-authors).

Conference presentation: part of this paper was presented at ECOBIM meeting, 2016 May-June, Le Havre, France.

This work is licensed under a Creative Commons Attribution NonCommercial 4.0 License (CC BYNC 4.0).

(C) Copyright S. Slaby et al., 2016

Licensee PAGEPress, Italy

Journal of Xenobiotics 2016; 6:6587

doi:10.4081/xeno.2016.6587

control organism (yellow dotted line, Figure 2D). Then, in order to highlight subtle alterations, a second normalization was achieved: each measurement was expressed as a function of studied tadpole length (colored bars). Thus, for treated tadpole A, it appeared that even if the individual was smaller (length, grey bar) the other measured parameters were over-size compared to untreated tadpole (colored bars).

\section{Conclusions}

The new method we propose presents several advantages compared to the traditional ones. Indeed, automated segmentation and detection allow automated quantification of tadpole's morphology and anatomy. In this paper, we focused on several parameters such as perimeter or distance between eyes, but numerous others can be obtained from segmented images (i.e., branchial arches or brain size and morphology, etc.). Thus, from the high quality of each individual description, it answers to the ethical principles of the 3R's, first stated by Russell and Burch in $1959,{ }^{15}$ by decreasing the number of tadpoles needed to 


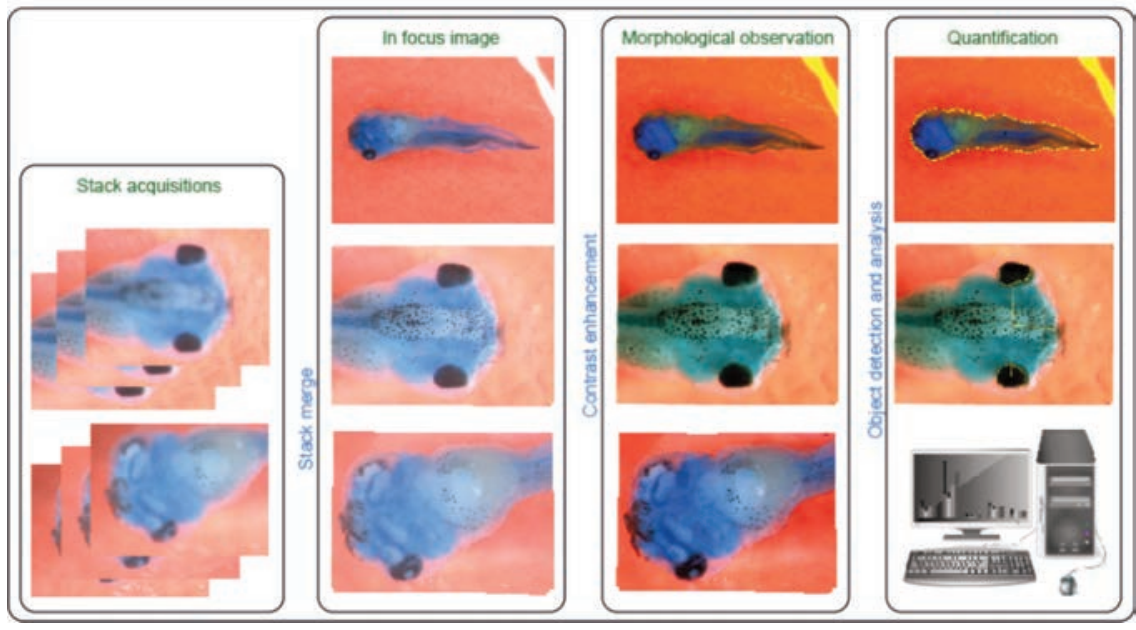

Figure 1. Logical scheme of image improvement and analysis for biometric criteria quantification. Morphological observation results in binary information such as spinal cord or organs integrity, while objects detection and segmentation provides quantitative biometrical description of each tadpole.

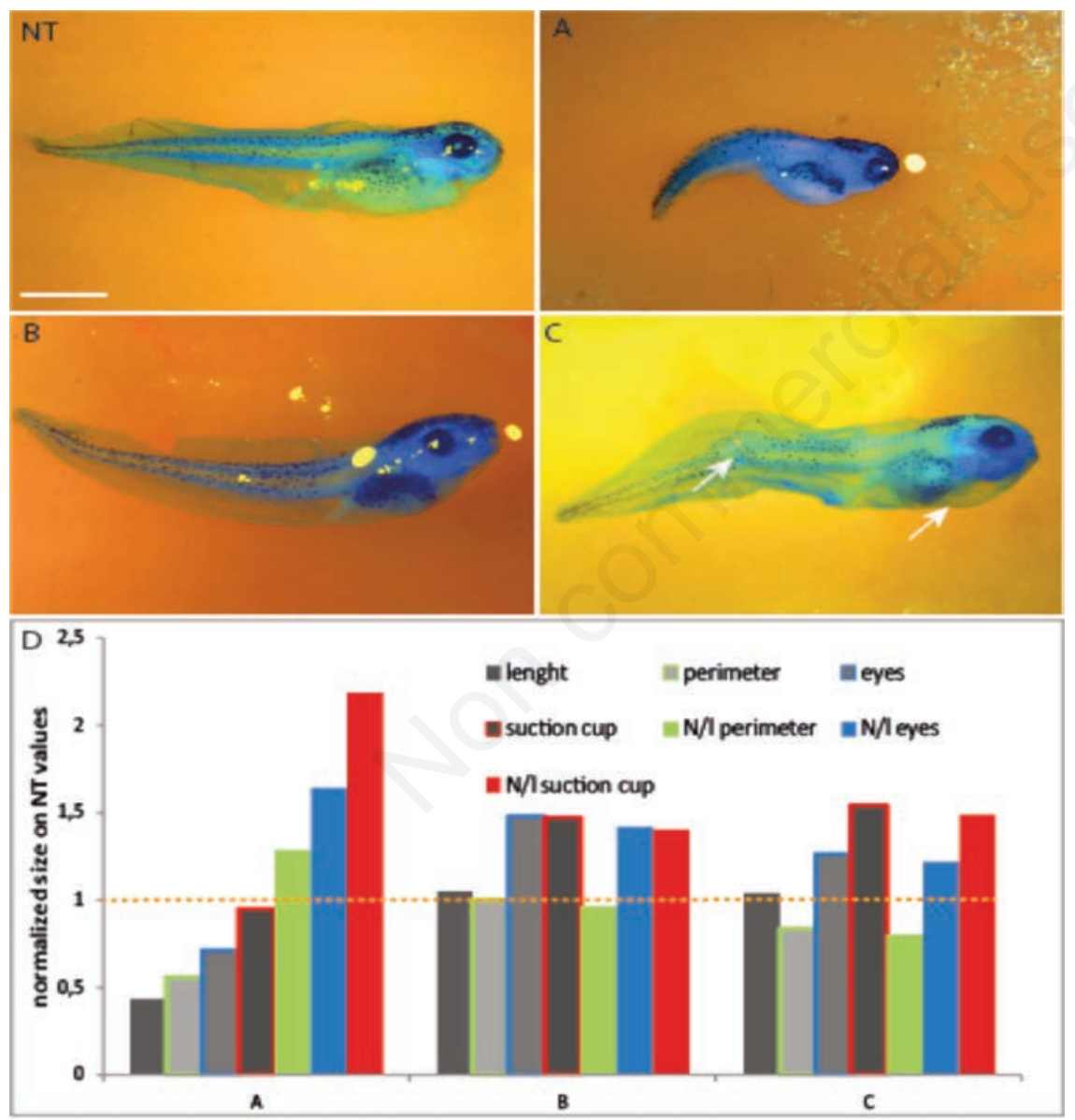

Figure 2. Biometric analysis of 4 different tadpoles. NT corresponds to non-treated animal while A-C are tadpoles grown in contaminated environment. White arrows illustrate some of the morphological defects enlightened by the image improvement step. D corresponds to biometrical quantification from A-C normalized on measurements performed on NT, with: i) length and perimeter; ii) eyes, corresponding to the distance between the both animal's eyes centroids in ventral position; iii) suction cup corresponding to the distance between the isobarycenter of both eyes and the suction cup. N/1 stands for the parameters also normalized on the length of the concerned animal. Doted orange line corresponds to NT. Scale bar $1 \mathrm{~mm}$. achieve precise estimation of xenobiotic impact. Then, each contaminant results in a specific biometric signature, an even more efficient biomarker. Thus, this biometric data assessment appears as an effective tool for environmental biomonitoring.

\section{References}

1. Monastersky R. Biodiversity: life - a status report. Nature 2014;516:158-61.

2. Blaustein AR, Romansic JM, Kiesecker JM, Hatch AC. Ultraviolet radiation, toxic chemicals and amphibian population declines. Divers Distrib 2003;9:123-40.

3. Blaustein AR, Wake DB. The puzzle of declining amphibian populations. Sci Am 1995;272:52-7.

4. Venturino A, Rosenbaum E, Caballero de Castro A, Anguiano OL, Gauna L, Fonovich de Schroeder T, et al. Biomarkers of effect in toads and frogs. Biomarkers 2003;8:16786.

5. Linder G, Lehman CM, Bidwell JR. Ecotoxicology of amphibians and reptiles. In: Sparling DW, ed. A nutshell, in ecotoxicology of amphibians. Pensacola: Society of Environmental Toxicology and Chemistry (SETAC); 2010. pp 69-103.

6. Dumont J. Frog embryo teratogenesis assay: xenopus (FETAX) - A short-term assay applicable to complex environmental mixtures. In: Waters M, ed. Short-term bioassays in the analysis of complex environmental mixtures III. New York: Springer; 1983. pp 393-405.

7. Mouche I, Malesic L, Gillardeaux 0. FETAX assay for evaluation of developmental toxicity, In: Gautier J-C, ed. Drug safety evaluation: methods and protocols. Totowa, NJ: Humana Press; 2011. pp 257-269.

8. Vismara C, Bernardini G, Bonfanti P, Colombo A, Camatini M. The use of in vitro fertilization in the frog embryo teratogenesis assay in xenopus (FETAX) and its applications to ecotoxicology. Sci Total Environ 1993;1:787-90.

9. Cailliau K, Browaeys-Poly E. A microinjectable biological system, the Xenopus oocyte, as an approach to understanding signal transduction protein function. Methods Mol Biol 2009;518:43-55.

10. Dumont JN. Oogenesis in Xenopus laevis (Daudin). I. Stages of oocyte development in laboratory maintained animals. J Morphol 1972;136:153-79.

11. Nieuwkoop PD, Faber J. Normal table of Xenopus laevis (Daudin): a systematical and chronological survey of the development from the fertilized egg till the end of metamorphosis. Princeton, NJ: Garland Publishing, Inc.; 1994. 
12. Marin M, Slaby S, Marchand G, Demuynck S, Friscourt N, Gelaude A, et al. Xenopus laevis oocyte maturation is affected by metal chlorides. Toxicol Vitro 2015;29:1124-31.

13. Slaby $\mathrm{S}$, Lemière $\mathrm{S}$, Hanotel $\mathrm{J}$, Lescuyer $\mathrm{A}$,
Demuynck S, Bodart JF, et al. Cadmium but not lead exposure affects Xenopus laevis fertilization and embryo cleavage. Aquat Toxicol 2016;177:1-7.

14. Schindelin J, Arganda-Carreras I, Frise E, Kaynig V, Longair M, Pietzsch T, et al. Fiji: an open source platform for biological image analysis. Nature Meth 2012;9:67682.

15. Russell WMS, Burch RL. The principles of humane experimental technique. London: Methuen; 1959. 